\title{
Surgical fires: perioperative communication is essential to prevent this rare but devastating complication
}

\author{
M E Bruley
}

Qual Saf Health Care 2004;13:467-471. doi: 10.1136/qshc.2003.005819

A fire on or within a surgical patient is a continuing risk in modern surgery. Unfortunately, the sensitivity of surgical and anaesthesia staff to this hazard has waned over the past 25 years with cessation of the use of flammable anaesthetic agents. Prevention of surgical fires requires understanding the risks and effective communication between surgical, anaesthesia, and operating nursing staffs. Preventive measures exist but have yet to diffuse sufficiently across professional boundaries. Based on a review of relevant databases, decades of experience from field investigations, and a review of the medical literature, this paper discusses the incidence of surgical fires, the responsibility for prevention in the perioperative setting, and the procedures for surgical fire prevention and extinguishment.

Correspondence to: ME Bruley, Vice President, Accident and Forensic Investigation, ECRI, 5200 Butler Pike, Plymouth Meeting, PA 19462, USA; mbruley@ecri.org

Accepted for publication 14 August 2004
$\mathrm{T}$ he use of flammable anaesthetics largely ended in the 1970s and with it, presumably, went the notorious risk of a surgical fire. During the preceding decades this hazard was largely viewed as an ever present, but reasonably controllable, complication of surgery. At that time, prevention was considered to be within the domain of the anaesthesia staff. ${ }^{12}$ Today, the hazard of igniting a fire on or within a surgical patient is a continuing risk in surgery, but the sensitivity of surgical and anaesthesia staff to this hazard has waned.

This patient safety issue-albeit rare-is real, and surgical fires continue to occur with regrettable frequency and with serious or fatal results. ${ }^{3}$ As a patient safety issue, reducing the risk of surgical fire has recently been brought to the fore in the United States by the Joint Commission on Accreditation of Healthcare Organizations (JCAHO) as a formal national patient safety goal for facilities accredited for ambulatory surgery.

Preventing surgical fires requires understanding the risks and effective perioperative communication between surgical, anaesthesia, and operating nursing staffs. Specific preventive measures exist but have yet to diffuse sufficiently across professional boundaries and are not yet ingrained in perioperative procedures. This paper discusses the incidence of surgical fires, the responsibility for their prevention in the perioperative setting, and the procedures for the prevention and extinguishment.

\section{INCIDENCE OF SURGICAL FIRES}

There has been no formal repository for statistics on the incidence of surgical fires. Based on a review of the medical literature, anecdotal reports received over the past 25 years, field investigations of such incidents, and searching of the US Food and Drug Administration (FDA) medical device problem reporting databases, it is estimated that in the US up to 100 minor surgical fires occur annually, with approximately 10 of these being serious and one or two fatal. ${ }^{3}$ This incidence is small in comparison with the more than estimated 23 million inpatient and 27 million outpatient surgical procedures performed each year in the US. ${ }^{56}$ These figures exclude the "miscellaneous diagnostic and therapeutic procedures" presented in the referenced data sources. Nonetheless, a surgical fire can be severely disfiguring or fatal and warrants attention by those concerned with providing safe health care.

One clear indication that surgical fires are continuing to occur can be seen by searching the FDA's Manufacturer and User Device Experience Network (MAUDE) database and the Medical Device Reporting (MDR) database (http:// www.fda.gov/cdrh/databases.html). For example, our search and review of reports in these databases for the 3.5 year span from January 1995 to June 1998 revealed 167 surgical fires. Of these, $56(33 \%)$ were airway or oropharyngeal fires, $47(28 \%)$ were fires on the head or neck, 40 (24\%) were fires ignited on the outside of the patient, and $24(14 \%)$ were fires within the patient but not in the airway (for example, within a thoracotomy incision).

No similar searchable databases in other countries are readily available to the public. However, in the UK the incidence of surgical fires related to flammable prepping agents or to high intensity endoscopic light sources has been sufficient for its Medical Devices Agency (MDA) to issue related alerts. ${ }^{78}$

With the abundance of high energy surgical ignition sources, flammable surgical materials, and the potential for open oxygen sources, the hazard of surgical fire is clearly still with us. This conclusion is also supported by continuing reports of surgical fires in the medical literature. $^{1-14}$ An expanded bibliography on surgical fires of more than 230 citations from 1969-2004 is available from the author via e-mail request.

\section{RESPONSIBILITY FOR PREVENTION OF SURGICAL FIRES}

Who is in the best position to prevent a fire during surgery? In large part, the answer 
IGNITION SOURCE Surgeons

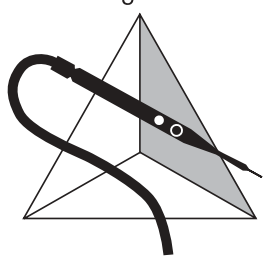

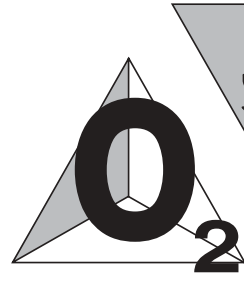

OXIDIZER

Anesthesia providers

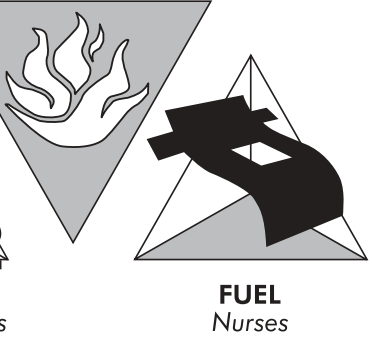

Nurses
Figure 1 Surgical fire triangle.

depends on the type of modern day surgical fire being discussed. Most of today's fires involve an oxygen enriched atmosphere beneath the drapes or in the airway. These include fires during head and neck surgery, tracheal tube ignition during tracheostomy, laser or electrosurgery ignited fires in the trachea or bronchus, and fires in the oropharyngeal cavity during tonsillectomy. ${ }^{3}{ }^{10}$ Furthermore, flammable alcohol based prepping agents have again come into favour with resultant fires. ${ }^{71}$

Since 1975 the ECRI has performed hundreds of investigations worldwide of surgical fire incidents in collaboration with the involved medical personnel. Historically, we have found that the best preventive measure is the most difficult to achieve-namely, establishing effective communication between two medical specialties: surgery and anaesthesiology. ${ }^{4}$

Unlike in the era of flammable anaesthetics, the risk of surgical fires is now insidious and preventive measures are no longer mainly in one professional domain (fig 1). Surgeons wield the ignition sources, anaesthesia personnel control the oxidizers (oxygen and nitrous oxide), and nursing personnel are frequently in control of safe use of the potential fuels (such as alcohol prepping solutions and tonsil sponges). There are many other flammable products present during surgery-patient hair, linens, dressings, ointments, breathing circuits, etc-all of which are even more easily ignitable in the presence of enriched oxygen microenvironments that are frequently present under the surgical drapes. The reality is that different staff are in the best position to prevent a modern day surgical fire at different times of the surgical procedure. Each profession-surgery, anaesthesia, and nursing - is in a position to control one leg of the "fire triangle", but to do so usually requires intraoperative collaboration with at least one of the other two professions. This makes implementation of surgical fire prevention methodologies uniquely complicated.

The diffusion and implementation of published surgical fire preventive recommendations appears to have been hindered by a rift in communication in the surgical setting about the causes of modern day surgical fires and the effective preventive measures that can be employed. The need for such effective communication on surgical fire causes and preventive measures is especially critical between the surgical and anaesthesia professions. For prevention of oxygen enriched surgical fires, the surgeon needs to be made aware that an oxygen enriched atmosphere may be present near or within the surgical site and, conversely, the anaesthesia staff needs to be forewarned about each use of an ignition source.

Communication on these issues during surgery is essential and must breach the boundaries of perceived professional territories. Education of clinical staff about the hazards of surgical fire is also essential, but is not currently addressed in most surgery or anaesthesia residency programs.

\section{Box 1 Extinguishing a surgical fire}

(1) Fighting fires on the surgical patient Emergency procedure

Review before each surgical procedure.

In the event of a small fire on the patient, immediately

- Pat out or smother the fire, or remove the burning material from the patient.

In the event of a large fire on the patient, immediately

- Stop the flow of breathing gases to the patient.

- Remove the burning material from the patient:

- have another team member extinguish the burning material;

- if needed, use a fire extinguisher to put out a fire involving the patient.

- Care for the patient:

- resume patient ventilation;

- control bleeding;

- evacuate the patient if the room is dangerous from smoke or fire;

- examine the patient for injuries and treat accordingly.

- If the fire is not quickly controlled, notify other operating room staff and the fire department that a fire has occurred:

- isolate the room to contain smoke and fire.

Save involved materials and devices for later investigation.

(2) Extinguishing airway fires

Emergency procedure

Review before each surgical intubation.

At the first sign of a tracheal tube fire, immediately and rapidly

- Disconnect the breathing circuit from the tracheal tube.

- Remove the tracheal tube:

- have another team member extinguish it;

- remove cuff protective devices and any segments of burned tube that may remain smouldering in the airway.

- Care for the patient:

- re-establish the airway and resume ventilating with air until certain that nothing is left burning in the airway, then switch to $100 \%$ oxygen;

- examine the airway to determine the extent of damage, and treat the patient accordingly.

Save involved materials and devices for later investigation. 


\section{Only You Can Prevent Surgical Fires \\ Surgical Team Communication is Essential}

The applicability of these recommendations must be considered individually for each patient.

\section{At the start of surgery:}

- Enriched $\mathrm{O}_{2}$ and $\mathrm{N}_{2} \mathrm{O}$ atmospheres can vastly increase flammability of drapes, plastics and hair. Be aware of possible enriched $\mathrm{O}_{2}$ enrichment under the drapes near the surgical site and in the fenestration, especially during head/neck surgery.

- Do not drape the patient until all flammable preps have fully dried.

- Fiberoptic light sources can start fires: Complete all cable connections before activating the source. Place the source in standby mode when disconnecting cables.

- Moisten sponges to make them ignition resistant in oropharyngeal pulmonary surgery.

For surgery with open delivery of supplemental oxygen:

- Question the need for $100 \% \mathrm{O}_{2}$ for open delivery during head/neck surgery.

- As a general policy, use air or $\leq 30 \% \mathrm{O}_{2}$ for open delivery to the face.

- Arrange drapes to minimize $\mathrm{O}_{2}$ buildup underneath.

- Keep fenestration towel edges as far from the incision as possible.

- Use an incise drape to isolate head and neck incisions from $\mathrm{O}_{2}$ and alcohol vapors.

- Coat head hair and facial hair (e.g., eyebrows, beard, moustache) within the fenestration with watersoluble surgical lubricating jelly to make it nonflammable.

- For coagulation, use bipolar, not monopolar electrosurgery.

\section{During oropharyngeal surgery:}

- Scavenge deep within the oropharynx with separate suction to catch leaking $\mathrm{O}_{2}$ or $\mathrm{N}_{2} \mathrm{O}$.

- Soak gauze or sponges used with uncuffed tracheal tubes to minimize gas leakage into the oropharynx, and keep them wet.

\section{When performing electrosurgery, electrocautery, or laser surgery:}

- Stop supplemental $\mathrm{O}_{2}$ (if $\mathrm{O}_{2}$ concentration is $>30 \%$ ) at least one minute before and during use of the unit, if possible.

- Activate the unit only when the active tip is in view (especially if looking through a microscope or endoscope).

- Deactivate the unit before the tip leaves the surgical site.

- Place electrosurgical electrodes in a holster or another location off the patient when not in active use (i.e., when not needed within the next few moments).

- Place lasers in standby mode when not in active use.

- Do not place rubber catheter sleeves over electrosurgical electrodes.

Reference: A clinician's guide to surgical fires: How they occur, how to prevent them, how to put them out. Health Devices 2003 Jan; 32(1):5-24. Poster is available free on the Internet at www.mdsr.ecri.org. For more information, or to order large full-color, glossy posters of "Only You Can Prevent Surgical Fires,"

\section{ECRI}

5200 Butler Pike, Plymouth Meeting, PA 194621298, USA

Tel: +1 (610) 825-6000 Fax: +1 (610) 834-1275 E-mail: info@ecri.org ( 2004 ECRI All rights reserved. Reprinted with permission

Figure 2 ECRI poster "Only you can prevent surgical fires".

Unfortunately, a number of references in the literature have presented incorrect information regarding the flammability of common fuels in the surgical setting and the appropriate actions to take to extinguish a surgical fire. ${ }^{15-17}$ Such incorrect information can complicate constructive dialogue between medical professionals. For example, Podnos and Williams ${ }^{15}$ sought to address these topics for the surgical community but their article contained significant errors. With regard to extinguishment, they suggest that the best course of action for staff in a surgical fire is to get a fire extinguisher, pull fire alarms, and to evacuate the area through emergency exits. These recommendations are absolutely wrong. There is no time to get a fire extinguisher (or fire blanket) when your patient is on fire; physically removing the burning materials from the patient is the first priority (and is typically done instinctively by the staff). Moreover, the bulleted guidelines for fire prevention in the article are limited and confusing, granting that they probably did not originate with the authors. Specifically:

- "Use only appropriately protected endotracheal tubes when operating near the trachea." This vague recommendation ignores differing ignition sources. Even laser resistant tubes will combust under certain circumstances, depending on oxygen concentration, laser wavelength, and tube materials. In addition, laser ignition resistant tubes are not resistant to electrosurgical ignition.

- "Use fire retardant surgical drapes." There are no fire retardant surgical drapes given the potential presence of oxygen enriched atmospheres and the high energy delivery 


\section{Key messages}

- Surgical fires are a preventable hazard.

- Success in preventing surgical fires requires understanding the fire risks and good perioperative communication between surgeon, anaesthesia staff, and nurses.

- The most common precursor to surgical fires is the use of supplemental oxygen delivered in an open fashion to the face during monitored anaesthesia care.

- The need for $100 \%$ oxygen for open delivery during head/neck surgery should be questioned.

- Guidelines should be developed for minimising oxygen concentrations under surgical drapes.

- Surgical fires continue to occur with regrettable frequency-preventive recommendations and educational aides are freely available at www.mdsr.ecri.org.

of lasers. ${ }^{1314}$ No surgical drapes are treated with fire retardant, although some disposable drapes do have a degree of ignition resistance in air.

- The fire hazards of Betadine and iodine are misrepresented, suggesting that both are flammable. Only tinctures of Betadine or iodine are flammable. Standard Betadine scrub and paint are non-flammable aqueous solutions.

\section{PREVENTION PRACTICES}

Cogent, well researched recommendations for preventing surgical fires are available. The poster entitled "Only you can prevent surgical fires" (fig 2) provides a summary of specific preventive recommendations for medical and nursing staffs and may be freely reproduced. Clinicians should note that the applicability of the recommendations to any one patient must be considered individually for the needs of that patient. The poster and many other publications on this topic are available without restriction at ECRI's free clinical website called Medical Device Safety Reports (www.mdsr.ecri.org, search term "fires").

The Joint Commission for the Accreditation of Healthcare Organizations (JCAHO) in the US recently published an alert to healthcare facilities with recommendations about surgical fire prevention and education. ${ }^{18}$ For 2005 the JCAHO has also established a formal patient safety goal to "reduce the risk of surgical fires" in ambulatory care settings. ${ }^{19}$ Those goals largely mirror the recommendations in the earlier JCAHO safety alert. They specify education for all surgical staff on "how to control heat sources and manage fuels" and require establishing "guidelines to minimizing oxygen concentrations under drapes." These accreditation based initiatives may well succeed where the hundreds of articles on the causes and prevention of surgical fires published over the past 30 years in surgical, anaesthesia, and operating room nursing medical literature have failed.

\section{EXTINGUISHING A SURGICAL FIRE}

The action needed to extinguish a surgical fire depends on whether the fire is burning in the airway or on the outside of the patient. As mentioned above, most staff react instinctively when a fire breaks out to remove the burning material from the patient. In addition to this, other procedures shown in box 1 are warranted. These procedures differentiate between extinguishing fires burning on the patient and for fires in the airway. ${ }^{3}$
Noteworthy citations that provide additional significant background and detail about the prevention of surgical fires are listed below under "Further reading".

\section{CONCLUSIONS}

Surgical fires are a preventable hazard. As with other low incidence but potentially serious or fatal medical misadventures such as wrong site surgery or retained instruments, solutions to prevent this hazard are known and published. However, preventive measures have yet to diffuse sufficiently across professional boundaries. The challenges to preventing fires relate to educating not one but three professions in the surgical setting —-surgery, anaesthesia, and nursing —and in breaching barriers to intraoperative communication.

\section{ACKNOWLEDGEMENTS}

The surgical fire photograph, the graphics, and poster included in this article are reproduced with permission from ECRI, 2003. ECRI (www.ecri.org) is a non-profit making health services research agency with headquarters in Plymouth Meeting, Pennsylvania, USA and international offices in London, Dubai, and Kuala Lumpur. Its mission is to improve the safety, quality, and cost effectiveness of health care. Its focus is healthcare technology, healthcare risk and quality management, and healthcare environmental management. ECRI is a designated Collaborating Center of the World Health Organization (WHO) and an Evidence-based Practice Center (EPC) of the US Agency for Health Research and Quality (AHRQ).

\section{REFERENCES}

1 MacDonald AG. A short history of fires and explosions caused by anaesthetic agents. Br J Anaesth 1994;72:710-22.

2 Macdonald AG. A brief historical review of non-anaesthetic causes of fires and explosions in the operating room. Br J Anaesth 1994;73:847-56.

3 de Richemond AL, Bruley ME. Head and neck surgical fires. In: Eisele DW, ed. Complications in head and neck surgery. St Lovis: Mosby-Year Book, 1993.

4 ECRI. A clinician's guide to surgical fires: how they occur, how to prevent them, how to put them out [guidance article]. Health Devices 2003;32:5-24.

5 Hall MJ, Owings MF. 2000 National Hospital Discharge Survey. Advance data from vital and health statistics. No 329. Hyattsville, Maryland: National Center for Health Statistics, 2002.

6 Hall MJ, Lawrence L. Ambulatory surgery in the United States, 1996. Advance data from vital and health statistics. No 300 . Hyattsville, Maryland: National Center for Health Statistics, 1998.

7 Medical Devices Agency (MDA). Use of spirit-based solutions during surgical procedures requiring the use of electrosurgical equipment [MDA Safety Warnings online]. SN2000(17). October 2000 (accessed 30 January 2003). Available at http://www.medical-devices.gov.uk.

8 Medical Devices Agency (MDA). Light sources and light guides for endoscopic use [MDA Safety Warnings online]. SN9841. November 1998 laccessed 30 January 2003). Available at http://www.medical-devices.gov.uk.

9 Reyes RJ, Smith AA, Mascaro JR, et al. Supplemental oxygen: ensuring its safe delivery during facial surgery. Plast Reconstr Surg 1995:95:924-8.

10 Greco RJ, Gonzalez R, Johnson P, et al. Potential dangers of oxygen supplementation during facial surgery. Plast Reconstr Surg 1995;95:978-84.

11 ECRI. Surgical fire hazards of alcohol. Health Devices 1999;28:286.

12 ECRI. Educational videos on surgical fires [evaluation]. Health Devices Health Devices 2003;32:25-36.

13 ECRI. Surgical drapes [evaluation]. Health Devices 1986;15:111-36.

14 ECRI. Laser ignition of surgical drapes [supplementary testing]. Health Devices 1992;21:15-6.

15 Podnos YD, Williams RA. Fires in the operating room. Bull Am Coll Surg 1997;82:14-7.

16 Stouffer DJ. Fires in operating rooms: an unrecognized problem? Firehouse $1991 ; 16: 30-3$

17 Weinbaum W, Hathcock G, Whalen T, et al. Here's how to prevent laser fires in the OR. Health Facil Mgmt 1998;11:29-30.

18 Joint Commission on Accreditation of Healthcare Organizations (JCAHO) Sentinel event alert: preventing surgical fires. June 2003 laccessed 22 July 2004). Available at http://www.jcaho.org/about+us/newstletters/ sentinel+event+alert/sea_29.htm.

19 Joint Commission on Accreditation of Healthcare Organizations (JCAHO) 2005 Ambulatory care national patient safety goals. July 2004 (accessed 22 July 2004). Available at http://www.jcaho.org/accredited+organizations/ patient+safety/05+npsg/05_npsg_amb.htm.

\section{FURTHER READING}

1 Bennett JA, Agree M. Fire in the chest. Anesth Analg 1994;78:406

2 Barker SJ, Polson JS. Fire in the operating room: a case report and laboratory study. Anesth Analg 2001;93:960-5.

3 Bruley ME, de Richemond AL. Supplemental oxygen versus latent alcohol vapors as surgical fire precursors. Anesth Analg 2002;95:1459. 
4 Bruley ME, Lavanchy C. Oxygen-enriched fires during surgery of the head and neck. In: Stoltzfus J, Benz FJ, Stradling JS, eds. Symposium on flammability and sensitivity of materials in oxygen-enriched atmospheres. Volume 4. West Conshohocken, PA: American Society for Testing and Materials, 1989:392.

5 de Richemond AL, Bruley ME. Insidious iatrogenic oxygen-enriched atmospheres as a cause of surgical fires. In: Janoff DD, Stoltzfus JM, eds. Flammability and sensitivity of materials in oxygen-enriched atmospheres. Volume 6. West Conshohocken, PA: American Society for Testing and Materials, 1993:66-73.

6 Dorsch JA, Dorsch SE. Hazards of anesthesia machines and breathing systems. In: Understanding anesthesia equipment. 3rd ed. Baltimore: Williams \& Wilkins, 1994:325-61.

7 ECRI. The patient is on fire!: a surgical fires primer [guidance article]. Health Devices 1992;21:19-34.

8 ECRI. Fires from oxygen use during head and neck surgery [hazard report]. Health Devices 1995;24:155-7.

9 ECRI. Laser-resistant tracheal tubes [evaluation]. Health Devices 1992:21:4-14.

10 Galapo S, Wolf GL, Sidebotham GW, et al. Laser ignition of surgical drapes in an oxygen enriched atmosphere. Anesthesiology 1998;89:A580.
11 Hirshman CA, Smith J. Indirect ignition of the endotracheal tube during carbon dioxide laser surgery. Arch Otolaryngol 1980;106:639-41.

12 Hurt TL, Schweich PJ. Do not get burned: preventing iatrogenic fires and burns in the emergency department. Pediatr Emerg Care 2003;19:255-9.

13 Levy El. Explosions during lower bowel electrosurgery. Am J Surg 1954;88:754-8.

14 McCranie J. Fire safety in the operating room. Today's OR Nurse 1994; 16:33-7.

15 National Fire Protection Association. NFPA 99: standard for health care facilities. Quincy, Mass: National Fire Protection Association (NFPA), 1996.

16 Neufeld GR. Fires and explosions. In: Orkin FK, Cooperman LH, eds Complications in anesthesiology. Philadelphia: J B Lippincott, 1983:671-6.

17 Salmon L. Fire in the OR; Prevention and preparedness [home study program]. AORN J 2004;80:42-60.

18 Smith C. Surgical fires: learn not to burn [home study program]. AORN J 2004;80:24-40.

19 Wolf GL, Simpson Jl. Flammability of endotracheal tubes in oxygen and nitrous oxide enriched atmosphere. Anesthesiology 1987;67:236-9.

20 Wolf GL, Sidebotham GW, Lazard JL, et al. Laser ignition of surgical drape materials in air, 50\% oxygen, and $95 \%$ oxygen. Anesthesiology 2004; 100:1167-71. 